\title{
FOCUSSING ON CONDITIONAL SENTENCES
}

\section{Kathryn Penwill}

The importance of "real" communication in the ESL classroom has often been repeated and certainly, students should be given plenty of opportunity to communicate in situations which are real, or as close to reality as possible. However, there may be times when one structure in particular is a stumbling block for the students, and some attention must be given to the problem area. The type of activity which would be helpful in this situation is one which guides the students' use of the language so that the structure in question is elicited and practiced. The activity should encourage a high level of student participation and it should be fun.

The activities described in this article attempt to fulfill these criteria in order to allow students to practice conditional sentences. They are appropriate for secondary and adult classes and could be adapted for use with children aged 10-12 years. They were written on the assumption that the students are aware of the following three basic types of conditional sentences:

1) Conditionals used to express a probable event:

e.g.: If I have enough time, I will visit you this evening.

If I have enough time, I always visit my friend in the evening.

2) Conditionals used to express an improbable event:

e.g.: If I weren't so tired this evening, I would visit you.

3) Conditionals used to express an impossible event:

e.g.: If I had been in the neighbourhood, I would have visited you this evening.

N.B. Note that in each of the three basic types of conditional sentences, there is an if clause, where a condition is put forth, and a result clause, which is either the probable, improbable or impossible consequence of the condition.

The aim of the following activities, then, is for students to practice using these sentence types.

\section{Activity 1: "One of those days!"}

A) Begin by asking students if any of them are superstitious. Tell them that you had a very bad day a while ago. Ask them to name the superstitions which you ignored and what the consequences were as you are telling your story.

Illustrate your experiences on the board as you talk about them, or prepare an overhead in advance. The illustrations need not be elaborate. Simple stick figures are very effective in making your ideas clear (see appendix for sample illustrations of the following story). 
Teacher: I got up at 7:30 A.M. as usual (picture 1) and looked at myself in the mirror, but I noticed that it was crooked, so I fixed it (picture 2). When I touched it, the hook came loose and the mirror fell on the floor and broke (picture 3). I went and got a broom and started cleaning up the mess, and I cut my finger (picture 4).

Student: If you break a mirror, you'll have seven years of bad luck.

Teacher: Next I had breakfast. I had scrambled eggs, and I always like to add a bit of salt (picture 5). So I reached for the salt shaker, and knocked it over (picture 6). I cleaned up the spilled salt, and when I sat down again, I missed the chair, and sat on the floor instead (picture 7).

Student: If you spill salt, you'll have bad luck.

Teacher: I started getting ready to leave for work, and as I was dressing, I noticed that it was raining (picture 8). Just my luck, I thought. You see, I always buy cheap umbrellas, because I lose them all the time, but they never work when I need them. So, I decided to try my umbrella before going out. I opened the umbrella and put it over my head (picture 9). I was delighted to see that it worked. But I knocked my favourite plant over as I put it up (picture 10).

Student: If you put an umbrella up in the house, you'll have bad luck. Teacher: I decided to clean up the mess later, because it was getting very late.

I rushed out the door and off to the bus stop. As I ran along, I didn't notice a ladder leaning against a building and across the sidewalk. I also didn't notice the open sewer hole on the other side (picture 11). I ran right under it and fell into the sewer hole (picture 12).

Student: If you walk under a ladder, you'll have bad luck.

Teacher: I crawled out, painfully, and continued on my way. I paused for a moment to let a black cat pass in front of me (picture 13), then slipped on a banana peel and fell flat on my nose (picture 14).

Student: If a black cat crosses your path, you'll have bad luck.

Teacher: I glanced at my watch as I struggled to my feet and saw that I had four minutes to catch the 8:30 bus (picture 15). "That bus is never early," I said. "I'm sure I won't miss it." I reached the corner at $8: 28$, just in time to see my bus driving past me (picture 16).

B) Have students work in pairs to figure out where you went wrong during your unlucky day. They can use the pictures you drew as reminders of the events in your day. For every superstition you ignored, students 
write sentences such as the following:

1) If you hadn't broken the mirror, you wouldn't have cut your finger.

2) If you hadn't spilled the salt, you wouldn't have fallen on the floor.

3) If you hadn't put up your umbrella in the house, you wouldn't have knocked over the plant.

4) If you hadn't walked under the ladder, you wouldn't have fallen in the sewer hole.

5) If a black cat hadn't crossed your path, you wouldn't have fallen on your nose.

\section{Activity 2: "Get Lucky"}

Students work in pairs. Each pair must think of one superstition which they write down twice, on separate pieces of paper. Cultural diversity should be encouraged, and the more far-fetched the superstition is, the better.

The teacher then collects the pieces of paper and mixes them up. S/he redistributes them, giving one paper to each student. (If there is an odd number of students, one group will write the same superstition three times on separate pieces of paper.) For example:

If you drop a knife, you'll

have a visit from a strange man.

The students must pretend that they believe the superstition which is written on the card they receive. Each person must find the other person who believes in the same superstition by asking their classmates questions. The answers should indicate whether or not they believe in the superstition (i.e., whether or not they have the same card). For example:

$S_{1}$ : What would you do if you saw a black cat?

$S_{2}$ : I'd go and pat it. ( $S_{2}$ does not have the same card.)

$\mathrm{S}_{1}$ : What would you do if you saw a black cat?

$S_{3}$ : I'd cross the street. ( $S_{3}$ does have the same card.)

\section{Activity 3: "Chain Reaction"}

Each student receives four cards on which they must write four different sentences with the same structure as the following:

"If I don't eat breakfast, I will be hungry during class."

The teacher collects the cards and mixes them up.

Students get into pairs and the teacher gives each pair eight cards. One student picks up a card and reads the sentence. The other student must 
make a new sentence out of it by taking the result clause, turning it into the if clause and making up a new result clause which is logical, given the meaning of the if clause. They must change the verb tense where necessary.

Example: 1. If I don't eat breakfast, I will be hungry during class.

2. If I am hungry during class, I won't be able to concentrate.

3. If I can't concentrate, I won't learn very much.

4. If I don't learn very much, I will fail the exam. etc...

Students try to keep each sentence going for as long as they can. When they can no longer continue, they pick a new card and start again. They can keep track of the number of sentences they were able to make from one card, and try to beat themselves next time.

\section{Activity 4: "I told you so"}

This is a role play.

A teenager comes home after a disastrous day in which everything went wrong. S/he had many accidents, broke things, lost things, forgot things, etc. The mother or father has a reply for every confession the teenager makes.

Example: Teenager: I failed my exam.

Parent: If you hadn't gone to the party last night, you would have passed your exam.

Students can invent the teenager's story and the parent's reply, but they must follow the structure of the conditional sentence used in the example, as this type of sentence is the most logical for the situation.

The preceding activities have the function of guiding the language produced by students so that they can practice using conditional sentences.

Activities which are amusing and only moderately manipulative help to find a happy medium between a rigid structural approach and a communicative approach, where the teacher has a minimal amount of control over the language produced by the students. Such activities are sometimes necessary in order to concentrate on a specific language problem.

\section{REFERENCES}

Mendenhall, M. (1982). Teaching the conditionals. Modern English Teacher, 10(2), 36-37.

Yates, J.S. (1981). Using the blackboard. TESL Talk, 12(3), 48-61. 
THE AUTHOR

Kathryn Penwill has both a B.A. in French language and literature and a Diploma in Education specialized in the teaching of French as a second langage. She is now teaching ESL to adults in Montreal and working towards a Certificate in TESL at McGill University.

APPENDIX

Picture Story to Accompany Activity 1

1.

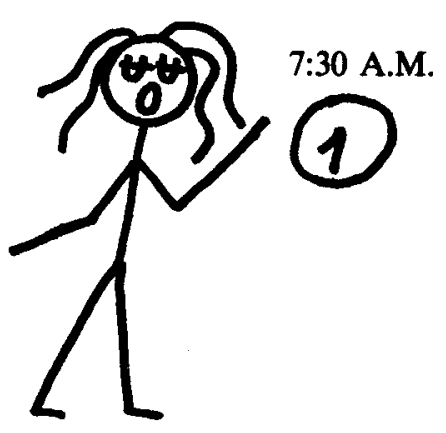

3.

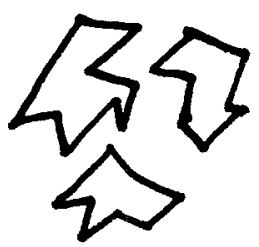

2.

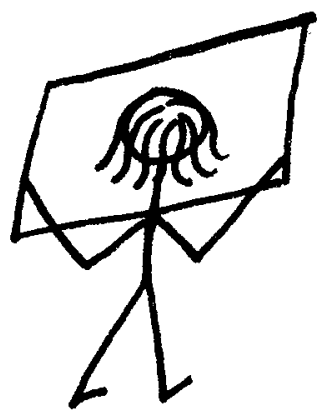

4.

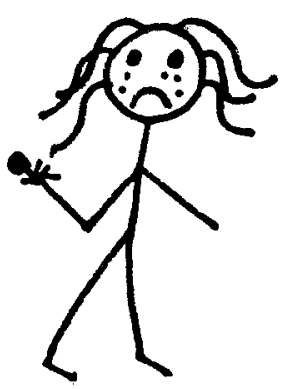

6.

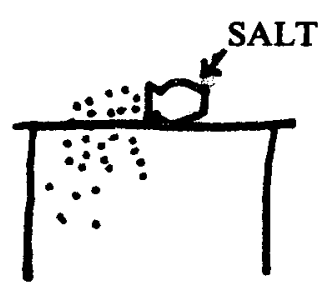

5.

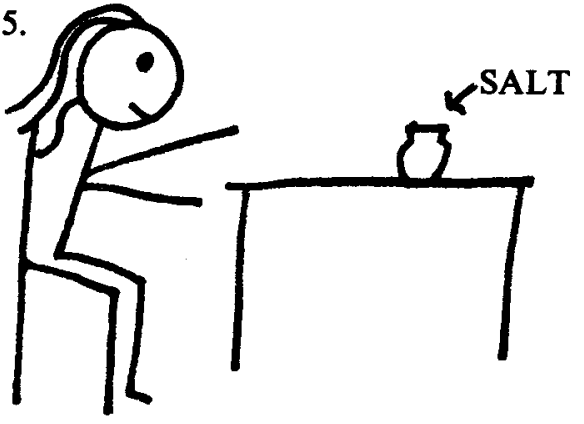

IN THE CLASSROOM/EN LASE

83 
7.
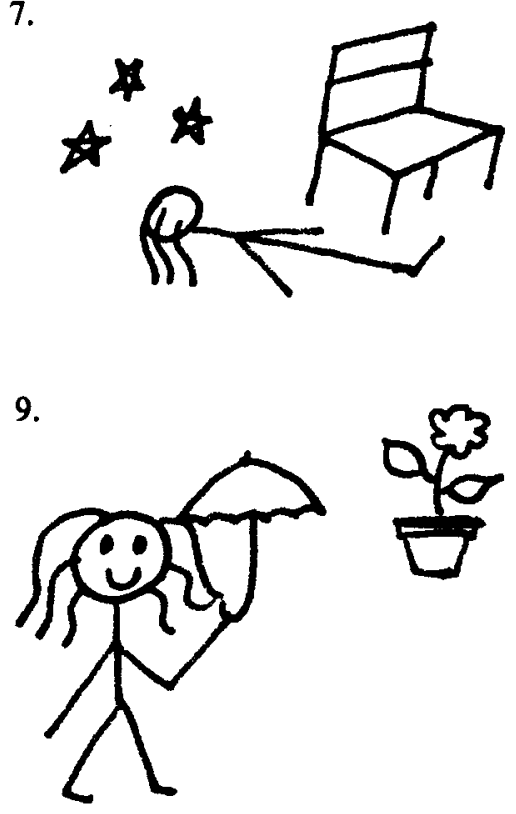

9.

11.

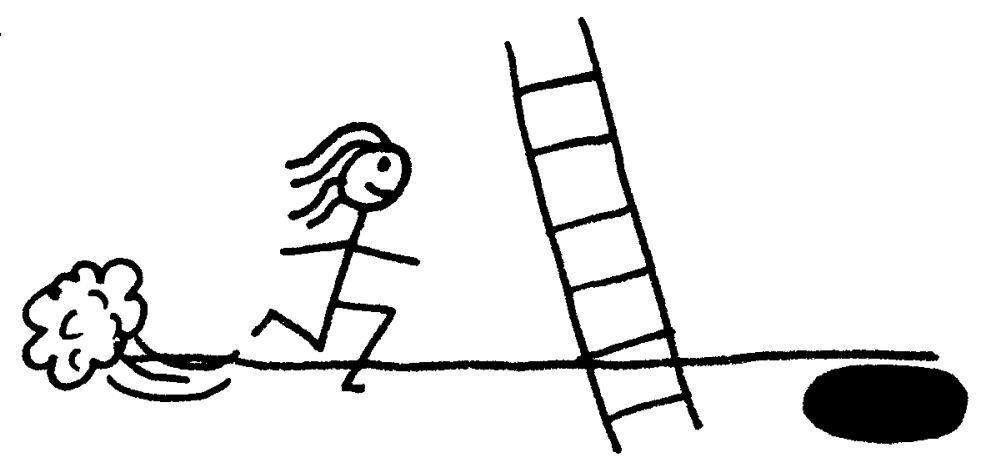

12.
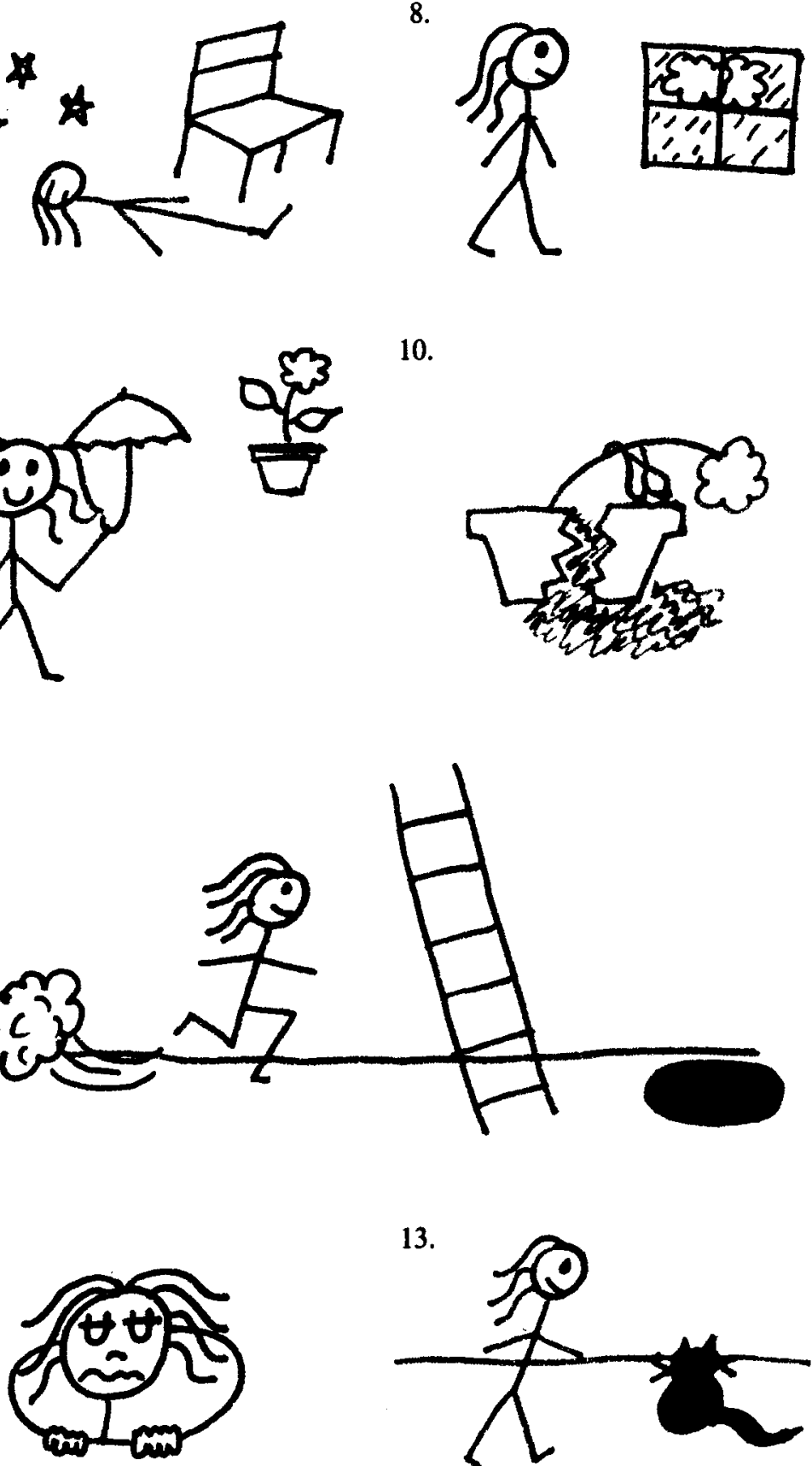

10.
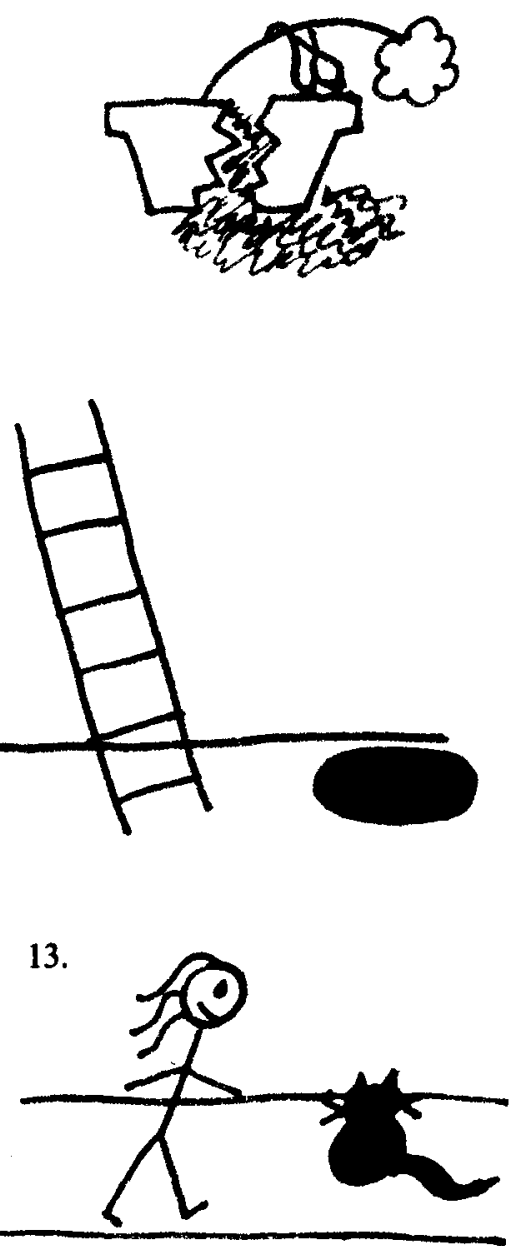

TESL CANADA JOURNAL/REVUE TESL DU CANADA VOL. 2, NO. 2, MARCH 1985. 
14.

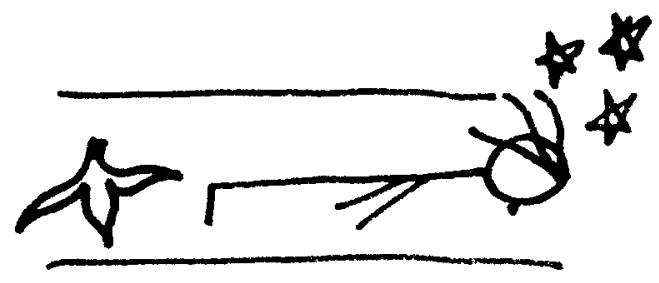

15.

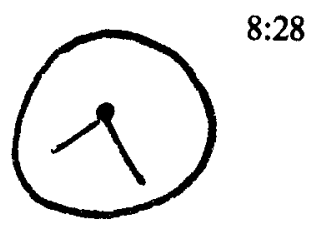

16.

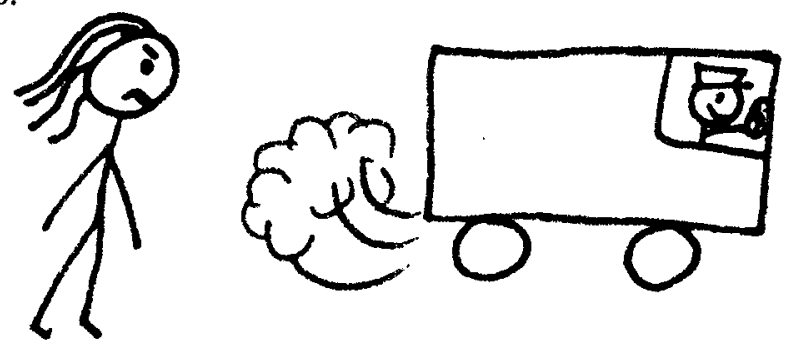

IN THE CLASSROOM/EN CLASSE

85 